\title{
Modelos literarios y fuentes mitográficas de la carta de Cánace (Heroidas 11)
}

Laura Camino Plaza

Universidade de Santiago de Compostela, España

Icaminoplaza@gmail.com

Recibido: 14/04/2020. Aceptado: 16/08/2020.

\begin{abstract}
Resumen
La historia de Cánace y Macareo se encuentra recogida en la Heroida 11, siendo lugar común considerar que su modelo literario es el Eolo de Eurípides. En este trabajo se da cuenta de la ambigüedad presente en Heroidas 11 con relación a la identificación de Eolo como padre de Cánace y Macareo, confusión que inevitablemente nos remonta a un problema mitográfico de mayor alcance. Por último, se analizan las conexiones y desviaciones temáticas entre Heroidas 11 y Eolo a partir de la edición de POxy 2457.
\end{abstract}

PALABRAS CLAVE: Heroidas, Eolo, Ovidio, Eurípides, mitografía.

\section{Literary models and mythographical sources of Canace's letter (Heroides 11)}

\begin{abstract}
The story of Canace and Macareus is contained in Heroides 11. It is usual to consider its literary model to be the Aeolus of Euripides. In this paper we point out the ambiguity present in Heroides 11 in relation to the identification of Aeolus himself as father of Canace and Macareus. This ambiguity will inevitably guide us back to a mythographical problem of greater scope. Finally, we analyze the thematic connections and deviations between Heroides 11 and Aelous, taking POxy 2457 as a reference.
\end{abstract}

KEYWORDS: Heroides, Aeolus, Ovid, Euripides, mythography. 


\section{Introducción}

El Eolo de Eurípides ha sido comúnmente aceptado como el texto fuente en el que Ovidio se basó para escribir la epístola 11 de sus Heroidas, si bien es cierto que la obra euripidea se conserva en un estado muy fragmentario. Supone esta fragmentariedad una dificultad añadida a la confusión que, tanto en la carta ovidiana como en los testimonios de los mitógrafos antiguos, encontramos en torno a la figura del Eolo padre de Cánace y Macareo. Teniendo esto en cuenta, y con el fin de poder entender mejor las diferentes lecturas que surgen del contraste de la carta ovidiana con las demás fuentes que presentan la misma historia, se antoja necesaria una breve contextualización de la trama del mito de Cánace según Ovidio.

Nos cuenta el sulmonés en su epístola que Cánace y Macareo, hijos de Eolo, mantienen una relación incestuosa, fruto de la cual engendran un hijo. La muchacha, primeriza en el amor y asustada por el crimen ("tua crimina" [tu crimen] Ep. 11.51) $)^{1}$ que carga en su vientre, oculta a Macareo sus intentos de interrumpir el embarazo, tentativas que finalmente no llegan a buen puerto. Cuando se acerca el momento del parto, asistida por su nodriza y acompañada por Macareo, ${ }^{2}$ la moribunda Cánace, gracias a la promesa de matrimonio que le hace su hermano, logra sacar fuerzas para sobrevivir y dar a luz al hijo de ambos. La nodriza sabe que ha de proteger al niño de Eolo y por ello finge realizar un sacrificio ocultando al recién nacido entre ramos de oliva y livianas cintas, ${ }^{3}$ de modo que la muchedumbre y el propio rey le dejen paso y pueda salir con el bebé del palacio. Pero cuando está ya muy cerca de la puerta el llanto del niño revela la farsa y Eolo le arrebata a la criatura. Corre el rey hacia Cánace y divulga a gritos el motivo de su vergüenza, ${ }^{4}$ al mismo tiempo que ordena que su nieto sea abandonado y devorado por perros y aves. Finalmente, y tras recibir de manos de un hombre enviado por su padre una funesta espada, Cánace se dispone a suicidarse. La muchacha afronta su futuro con determinación a la vez que un profundo dolor por la pérdida de su inocente hijo le sobrecoge el alma. Es entonces, en este crítico momento, cuando escribe la carta a su hermano.

\section{Problemas de identificación: Eolo I, II y III.}

El mito de Cánace tratado por Ovidio resulta, a primera vista, sencillo. Sin embargo, un estudio mitográfico más pormenorizado nos muestra enseguida que no existe una identificación unívoca —ni en el texto ovidiano, ni en la tradición antigua en general- del padre de la heroína, Eolo. Normalmente,

\footnotetext{
1 A partir de ahora, cito por la edición y traducción de Moya (1986).

2 Para los lectores actuales, Macareo aparece de una manera muy extraña en escena: no habiendo ninguna mención a que este se encontrase también en el lugar del parto, Cánace introduce las palabras que le dirige para animarla a luchar por su vida y la de su hijo; también para proponerle matrimonio. Es la única intervención, reproducida por Cánace en estilo directo, que tenemos de Macareo en la carta. Quizás esta súbita aparición del amante en escena sea reflejo de su comportamiento en el Eolo euripideo, aunque lamentablemente no podemos estar seguros.

3 "et levibus vittis" [y con ligeras vendas] (Ep. 11.70). Se trata de un frecuente símbolo de castidad. Jacobson (1974:170) toma esta explícita mención a las vittae o cintas como deliberada y se pregunta si la ironía que surge de ocultar una falta religiosa como es este nacimiento con una ceremonia falsa se remontará a Eurípides o si, por el contrario, se trata una innovación ovidiana.
}

4 Encontramos de nuevo otra laguna en el sentido general del texto ovidiano. En ningún momento se nos explica cómo Eolo sabe que ese hijo es de Cánace y mucho menos si conoce o no que el padre es Macareo. 
las tradiciones mitográficas y literarias antiguas distinguen tres Eolos. ${ }^{5}$ Como se demostrará a continuación, en Heroida 11 Ovidio confunde al Eolo rey de los vientos, el que aparece en la Odisea y la Eneida, con el Eolo hijo de Helén, responsable de una importante genealogía. Veamos cómo en su carta el sulmonés mezcla características de ambos personajes y a qué se puede deber esta confusión.

Existe un Eolo (a partir de ahora, Eolo I) que la tradición nos ha transmitido como hijo de Helén y de la ninfa Orseide y, en consecuencia, nieto de Deucalión y Pirra. Los hermanos de este Eolo, héroe epónimo ancestro de los eolios, eran Doro y Juto, cuyos respectivos descendientes fueron los dorios y los jonios. Eolo I reinó en Magnesia, Tesalia, donde se casó con Enáreta, hija de Deímaco, con quien tuvo siete hijos: Creteo, Sísifo, Atamante, Salmoneo, Deyón, Magnes y Perieres. Algunas tradiciones añaden a Macareo, Etlio y Mimante. También tuvo cinco hijas, a saber: Cánace, Alcíone, Pisídice, Cálice y Perimede, a las que algunos autores añaden Tanagra y Arne. ${ }^{6}$

Así las cosas, todo indica que los Cánace y Macareo de Heroida 11 son hijos de este Eolo I, hijo de Helén. Es importante pararse un momento sobre la figura de Helén, descendiente directo de Deucalión y precursor de un relevante linaje, puesto que nos puede ayudar a entender un fragmento de la carta ovidiana que enseguida mostraré.

En su estudio de la mitología griega, López Eire y Velasco López (2012: s.v. Helén) apuntaron que los griegos creían ser todos de la misma raza por tener a Helén como antepasado común, "nombre del que derivaba el de los griegos o helenos (héllenes)". Por otro lado, tal y como recogió Ruiz de Elvira (1982:264), "en Hesíodo fr.5 M-W ([...] confirmado por Filastrio, Diversarum haereseon liber 111, p. 76 Migne $=277$ ed. Corp. Christian.) se dice que hubo una Pandora, hija de Deucalión, que tuvo de Zeus un hijo llamado Greco". En Filastrio, todavía según Ruiz de Elvira, "parece haber habido confusión entre ese Greco, nieto de Deucalión, y Helén el hijo de Deucalión". ${ }^{7}$ Teniendo esto en cuenta, parece que ahora se entiende mejor el dato apolodoreo según el cual Helén dio su nombre a los que antes se llamaban 'grecos', de donde vendría el nombre de griegos, sustituido después efectivamente por el de héllenes (Ruiz de Elvira, 1982:263-264).

Como acabo de adelantar, este dato es importante porque podría arrojar luz sobre los problemáticos versos 19-20 de Heroidas 11, donde Cánace dice ser descendiente de Júpiter: "Quid iuuat admotam per auorum nomina caelo / Inter cognatos posse referre Iouem?" [¿De qué me sirve, emparentada con el cielo por los nombres de mis antepasados, poder nombrar a Júpiter entre mis parientes?]. Ninguno de los dos Eolos que a lo largo de la carta ovidiana se confunden, ni tampoco sus esposas, cuentan con Júpiter entre sus ascendientes. Una explicación que encuentro plausible para estos versos es que Ovidio también confunda a Greco (hijo de Júpiter y nieto de Deucalión, según Filastrio a partir de Hesíodo) con Helén, tradicionalmente considerado, como hemos

5 Un cuarto Eolo designaría al gigante troyano asesinado por Turno. Véase el recuento que elaboró Blázquez (2005: s.v. Eolo).

6 Véase Grimal (1981: s.v. Eolo).

7 Ruiz de Elvira (1982:264) reconoció que "no se puede saber hasta dónde llega en él [Filastrio] la cita de Hesíodo, que en éste figuraba ya la derivación "Helenes de Helén", cosa que no está en el fragmento griego propiamente dicho". 
señalado, hijo de Deucalión y abuelo de Cánace. ${ }^{8}$ De todos modos, no hay que descartar la posibilidad de que la relación entre Júpiter y Eolo ya se diese en el Eolo euripideo, a la luz del fragmento 14 que Nauck (1889:366) atribuyó a la tragedia perdida y en el que se presenta a Helén como hijo de Júpiter y padre

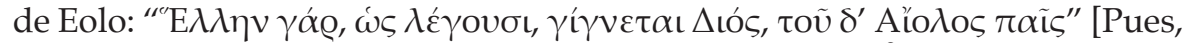
según se dice, Helén nació de Zeus, y es padre de Eolo"]. ${ }^{9}$

El Eolo II sería nieto de Eolo I, al ser hijo de Arne (a menudo llamada Melanipa, sobre la que ya escribió Eurípides en dos tragedias perdidas ${ }^{10}$ y Posidón. ${ }^{11}$ Es, asimismo, el hermano de Beoto. Los problemas de identificación entre ambos Eolos no serían tales si no contásemos con un tercero, aquel que es denominado 'señor de los vientos' y cuyas menciones más importantes aparecen en Odisea 10.1-27 y Eneida 1.51-86.

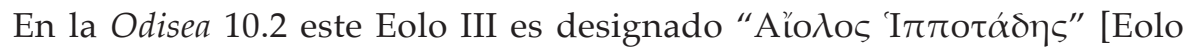
Hipótada] y de él se dice que es padre de seis hijos y seis hijas a los que ha

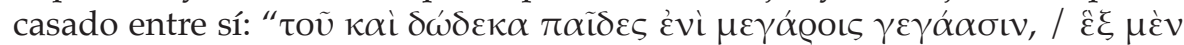

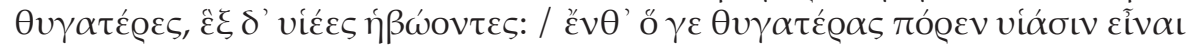

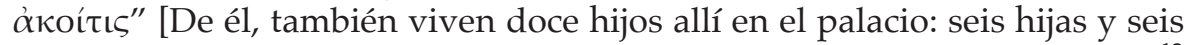
hijos, de edad floreciente. A los hijos les dio las hijas, para que fueran esposas $]^{12}$ (Od. 10.5-7). Grimal (1981: s.v. Eolo) no lo considera un personaje diferente, sino que cree que normalmente es confundido con el Eolo II, nieto del Eolo I, aunque afirma que a veces también aparece asimilado a este último. Por su parte, Ruiz de Elvira (1982:310), apoyándose en el testimonio de Diodoro Sículo $^{13}$ (según el cual habría un tercer Eolo claramente diferenciado, hijo de un Hípotes que sería hijo de un Mimante, que a su vez sería hijo del Eolo I) ${ }^{14}$, considera al 'señor de los vientos', el Hipótada de la Odisea, biznieto del Eolo I, es decir, del padre de Cánace y Macareo. Dicha hipótesis concuerda con el patronímico que se le da al 'señor de los vientos' en la Odisea, pero desconozco por qué dice Ruiz de Elvira (1982:310) que ese Eolo “confundido a veces con el Eolo hijo de Helén de cuya descendencia estamos tratando, es más usualmente considerado como hijo de un Hípotes", si reconoce que el testimonio sólo se encuentra en Diodoro. ${ }^{15}$

\footnotetext{
8 Cfr. la nota 16.

9 Sobre esta cuestión, véase Labate (1977:585-586).
}

10 Melanipa encadenada y Melanipa sabia. En su fábula 186, Higino atribuye a un tal Desmontes la paternidad de Melanipa, aunque reconoce que para 'otros poetas' el padre de Melanipa es Eolo: "Melanippen Desmontis filiam, siue Aeoli ut alii poetae dicunt, formosissimam Neptunus compressit, ex qua procreauit filios duos" [Neptuno se unió a la hermosísima Melanipe, hija de Desmontes o, como otros poetas dicen, de Eolo, de quien tuvo dos hijos]; cito por la traducción de Morcillo (2008). Para Grimal (1981: s.v. Desmontes) seguramente se trate de un error de interpretación por parte de Higino del título de la tragedia euripidea:

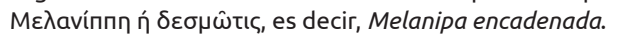

11 Para ver de manera más clara las relaciones familiares, consúltese el cuadro genealógico elaborado por López Eire; Henar Velasco (2012:782).

12 Cito el texto griego y la traducción a partir de la versión de Tapia (2017).

13 D.S. 4.67.3. Diodoro procura en esta parte de su libro juntar en un único árbol genealógico a los tres Eolos que reconocían - y confundían- las fuentes anteriores. Cfr. Torres (2004:169, n. 475).

14 Lo cierto es que, como ya mencioné antes de pasada, Grimal (1981) también reconoció a Mimante como posible hijo del Eolo I. Pero en su manual de mitología, en la entrada correspondiente a este personaje, sólo tenemos información referida al Mimante gigante, hijo de Urano, que combatió contra los dioses. En cuanto a Hípotes, Grimal (1981) recogió la posibilidad de que fuese uno de los Heraclidas - aunque sin darnos más información relevante, y ninguna que podamos relacionar con el testimonio de Diodoro-o que, en cambio, fuese el hijo de Creonte, el rey de Corinto que había acogido a Jasón y Medea.

15 La genealogía triple de Eolo, aunque artificiosa y con incoherencias, tiene pues su primer esbozo en la Bibliotheca Historica de Diodoro. Debo añadir que esta versión aparece corroborada en el escolio a Odisea 10.2 . 
El mismo Ruiz de Elvira (1970:303), en otro estudio más exhaustivo sobre esta cuestión, había afirmado que el Eolo Hipótada jamás es identificado con el Eolo II (el hijo de Posidón) como decía Grimal, sino con el Eolo I, el hijo de Helén. ¿En qué se basó para afirmar esto? Parece que en el hecho de que a ambos Eolos (es decir, al Eolo I, padre de Cánace, y al Eolo III, el Hipótada), les atribuyó la tradición el mismo número de hijos, doce, entre los que habría habido relaciones incestuosas. ${ }^{16}$ Para Ruiz de Elvira (1970:301-302) "la identificación no está expresa en ningún sitio, pero sí implícita en Ovidio, Her. 11.9-15" y parece confirmada también por Plutarco, quien en Parallela minora 312c nos habla de Eolo y Macareo, ahí calificado como el más joven de los doce hijos, y de la relación que este habría tenido con una de sus hermanas. A Ruiz de Elvira le interesó destacar de este último texto el hecho de que al Eolo padre de Macareo se le llamase rey de Tirrenia ("Aió

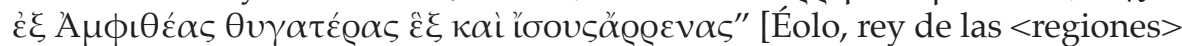
de Tirrenia, tuvo de Anfítea seis hijas y otros tantos varones $]^{17}$, lo que según él parecería implicar la identificación de los Eolos I y III. Cabe mencionar a este respecto que Diodoro (4.67.6) le atribuyó al Eolo hermano de Beoto (es decir, nuestro Eolo II) la llegada a las islas del mar Tirreno, que recibirían, a partir de él, el nombre de islas Eolias. Una vez allí, fundaría la ciudad de Lípara. Sin embargo, pese a sus intentos por establecer una genealogía única con tres Eolos bien diferenciados, Diodoro falló y acabó confundiendo a los Eolos II y III, pues más adelante (5.7.5) menciona que había sido el Eolo Hipótada quien se había establecido en las islas Lípari. ${ }^{18}$

Por otro lado, el testimonio de los versos 65 y siguientes del libro primero de Eneida, en los que Juno se dirige al Eolo 'señor de los vientos' para pedirle que destroce las naves de la raza enemiga suya que, procedente de Troya, surca el mar Tirreno en dirección a Italia, parece apoyar también la identificación del Eolo I y Eolo III:

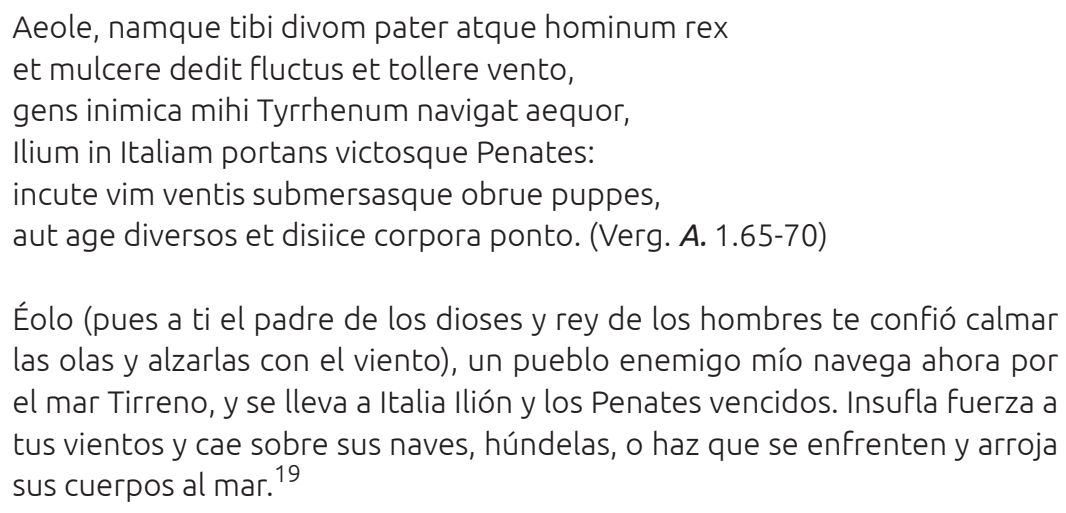

Si bien Ruiz de Elvira justificó, tal y como acabo de exponer, la identificación entre Eolo I y Eolo III a partir del paralelismo observado entre el testimonio ovidiano y el plutarquiano, cabe puntualizar que entre ambos textos las

\footnotetext{
16 Recuérdese que, según la Odisea, el Eolo III habría casado a sus hijos e hijas entre sí, mientras que el Eolo I habría interrumpido la relación existente entre sus hijos Cánace y Macareo, tal y como muestra la carta número 11 de las Heroidas. Por su parte, Casali (1998:708) anotó que en el escolio de la Odisea 10.7 se justificaba el incesto de los hijos de Eolo III recurriendo al matrimonio incestuoso del mismo Zeus con Hera, lo que ofrecería otra hipótesis diferente sobre los versos 19-20 de Heroida 11 antes comentados.

17 Cito desde la edición de Ibáñez (2014).

18 Véase Ruiz de Elvira (1970:302-3).
}

19 Cito por la edición de Fontán (1990). 
diferencias son también muy significativas. Para empezar, en Plutarco (Mor. 312c) no se nos da el nombre de la hermana con la que Macareo mantiene una relación y a la que deja embarazada. En segundo lugar, y aunque Ruiz de Elvira no lo señale, resulta muy relevante el hecho de que Plutarco utilice el verbo "ع̌ $\phi \theta \varepsilon\llcorner\varrho \varepsilon "$ (de $\phi \theta \varepsilon i ́(\omega$, 'destrozar') para hablar de dicha relación, al tratarse de un verbo con una fuerte carga semántica y que denota siempre violencia. Por ello, no parece descabellado pensar que a lo que está aludiendo Plutarco en su pasaje es a una violación más que a un romance entre ambos hermanos. De hecho, así lo entiende también Ibáñez (2014:375), que traduce todo el fragmento relativo a Eolo y Macareo de la siguiente manera:

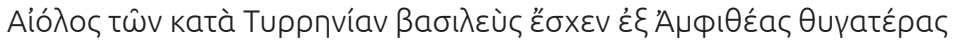

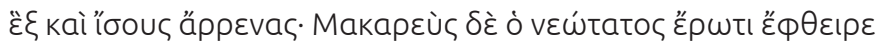

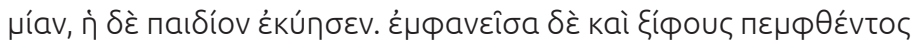

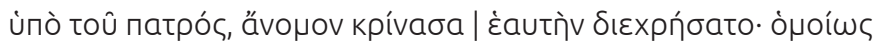

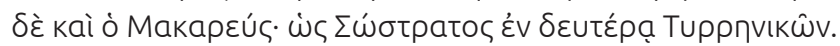
Éolo, rey de las <regiones> de Tirrenia, tuvo de Anfítea seis hijas y otros tantos varones. Macareo, el más joven, violó por amor a una y ésta quedó embarazada de un niño. Al ser descubierta, y como le fuera enviada una espada por su padre, se suicidó al considerar lo ilícito <de sus actos>, y lo mismo <hizo> Macareo. Así Sóstrato en el segundo libro de la Historia de Tirrenia. ${ }^{20}$

La hipótesis de una Cánace violada por su hermano ya la recogió Jacobson (1974:162), aunque lo que este investigador se estaba cuestionando en su estudio era el tipo de relación que habría entre los dos hermanos en Eurípides (no en Plutarco) a la luz del testimonio de POxy 2457, del que hablaré después. Jacobson mencionó que el uso del verbo $\delta \iota \alpha \phi \theta \varepsilon i ́(\omega$ ('arruinar', 'destrozar') en Eurípides, que puede admitir tanto el significado de seducir como el de violar, había ya implicado para Webster (1967:157) la existencia de un abuso sexual, algo que corroboran otras versiones antiguas de la misma historia. ${ }^{21}$ Según Jacobson (1974:163), esta teoría encuentra apoyo en Estobeo (Flor. 64.35), donde

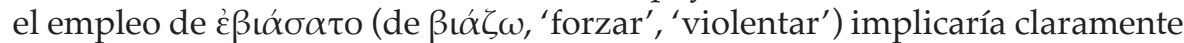
violación, no seducción. En esta línea de interpretación, pues, quisiera remarcar la importancia del testimonio de Plutarco (Mor. 312c), el cual, aunque nos ayuda a sostener la confusión entre Eolo I y Eolo III que aparecía también en Ovidio, muestra una visión muy diferente respecto a los motivos del incesto, como luego tendré ocasión de argumentar.

De todos modos, lo que sí parece innegable es que la identificación del Eolo I con el Eolo III tiene mucho que ver con que la tradición atribuyese a ambos personajes el mismo número de hijos y la existencia de relaciones incestuosas entre ellos. Ovidio, que en Heroidas 11 estaba hablando del Eolo I, padre de Cánace y Macareo, confundió a este con el Eolo III ya en los primeros versos de su carta, al atribuirle la capacidad de gobernar sobre los vientos:

Haec est Aeolidos fratri scribentis imago;

20 El único fragmento que conservamos de la Historia de Tirrenia de Sóstrato pertenece a su libro segundo (citado, como acabamos de ver, por Plutarco), de carácter mitográfico y transmitido por Stob. Flor. 4.20.72 = FGrH $23 \mathrm{~F}$ 3. Nótese que en esta versión Macareo se suicida, algo que no ocurre en la epístola ovidiana. A un Macareo dándose muerte a sí mismo lo tenemos también en Higino (Fab. 242), dedicada 'a los que se suicidaron', donde el autor recoge lo siguiente: "Macareo, hijo de Eolo, se mató a causa de su hermana Cánace, es decir, su prometida".

21 Jacobson (1974:162) cita en las notas a pie de página, ahora sí, la versión de Plutarco que estoy comentando, pero también scholia Ar. Nu. 1371 y Tz. ad Nu. 1371. 
Sic uideor duro posse placere patri.

Ipse nescis cuperem nostrae spectator adesset

Auctorisque oculis exigeretur opus.

Vt ferus et multoque suis truculentior Euris,

Spectasset siccis uulnera nostra genis.

Scilicet est aliquid cum saeuis uivere uentis;

Ingenio populi conuenit ille sui.

Ille Noto Zephyroque et Sithonio Aquiloni

Imperat et pinnis, Eure proterue, tuis;

Imperat heu! uentis, tumidae non imperat irae,

Possidet et uitiis regna minora suis. (7-18)

Ésta es la imagen de la hija de Éolo al escribir a su hermano. Me parece que así puedo agradar a mi severo padre. Me gustaría que él estuviese presente, como espectador de mi muerte, y que se acabase la obra a los ojos del autor. Como es cruel y mucho más amenazador que sus Euros, contemplaría mis heridas con mejillas secas. Ciertamente no es poco vivir con los salvajes vientos; él se amolda a la naturaleza de su pueblo. Manda sobre el Noto, el Céfiro y el sitonio Aquilón, y sobre tus alas, devastador Euro. Manda, jay!, sobre los vientos, no manda sobre su hinchada ira, y posee unos reinos menores que sus vicios. ${ }^{22}$

Pero la confusión parece estar manifiesta también en otro pasaje, el que comprende los versos 99-108, ya que Cánace reclama para sus hermanas unas bodas más felices que la suya, que se ha visto terriblemente truncada por su padre, lo que podría estar haciendo referencia a los matrimonios incestuosos llevados a cabo entre los hijos del Eolo Hipótada:

\author{
Scimus et utemur violento fortiter ense; \\ Pectoribus condam dona paterna meis. \\ His mea muneribus, genitor, conubia donas? \\ Hac tua dote, pater, filia diues erit? \\ Tolle procul, decepte, faces, Hymenaee, maritas \\ Et fuge turbato tecta nefanda pede. \\ Ferte faces in me, quas fertis, Erinyes atrae, \\ Et meus ex isto luceat igne rogus. \\ Nubite felices Parca meliore sorores, \\ Amissae memores sed tamen este mei. (99-108)
}

Lo comprendo bien, y me serviré con valentía de esta terrible espada. Hundiré el regalo de mi padre en mi corazón. ¿Tú, que me engendraste, con este presente dotas mi matrimonio? ¡Con esta dote, padre, tu hija será rica! Llévate lejos, Himeneo burlado, las antorchas nupciales y huye de este techo nefando con presuroso pie. Traed contra mí las antorchas que portáis, negras Erinias, y que mi pira se encienda con ese fuego. Casaos con mejor suerte, mis felices hermanas, pero acordaos, sin embargo, de mí, después de muerta.

Las ambigüedades presentes en Heroida 11 en torno a la figura de Eolo ayudan a visibilizar las dudas que todavía hoy suscita esta cuestión mitográfica. Pero

22 Esta imagen fiera y terrible de Eolo, que es mucho más cruel que los Euros a él sometidos, contrasta muy bien con la inocencia y candidez con la que es retratada Cánace. Ovidio maneja magistralmente estas diferencias a la hora de perfilar la personalidad de su heroína. A este respecto, Jacobson (1974:164) apuntó que, a pesar de que la paradoja de una persona capaz de ejercer control sobre otros, pero no sobre sí mismo, es un tópos común en muchas y diferentes manifestaciones (cfr. Ov. Ep. 12.167-168, 173-174), “the association of the character of Aelous with his function and environment is, as far as I know, found nowhere else, and is certainly typical of Ovid's wit and psychology". 
no solo eso. Dado que las epístolas ovidianas demandan siempre del público el ser leídas contra el telón de fondo de sus modelos literarios, las lagunas o anomalías que aparecen en la colección resultan ser también pistas para los lectores acerca de las fuentes originales que pudo haber usado el sulmonés. La aparentemente extraña referencia de Cánace a su boda frustrada apunta, de hecho, a la posibilidad de que este motivo estuviese presente en el drama euripideo y a que el propio trágico hubiese confundido también al padre de Cánace y Macareo con el Eolo Hipótada.

A la luz de esta idea, fijémonos un instante en la única intervención de Macareo que hay en Heroida 11:

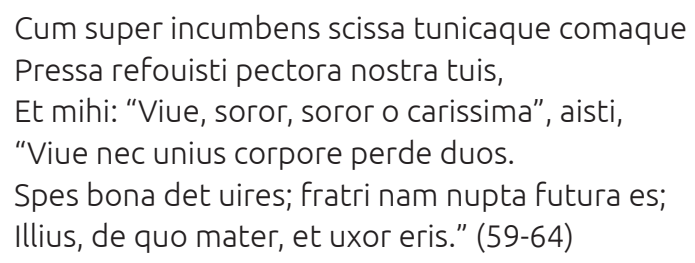

Cuando recostándote a mi lado, desgarrada tu túnica y tus cabellos, hiciste entrar en calor mi pecho al contacto del tuyo, y me dijiste: "Vive, hermana, o hermana queridísima, vive y no pierdas a dos en un solo cuerpo; que la buena esperanza te dé fuerzas; tú has de ser la esposa de tu hermano; serás la mujer del que te ha hecho madre.

¿Por qué Macareo está tan seguro de que podrá desposar a Cánace? ¿Por qué le asegura que se casará con ella? Ya Palmer (1898:381) en su antigua edición de las Heroidas, y partiendo de la idea de que la 11 se había basado en el Eolo de Eurípides, hizo una conjetura acerca del argumento de la tragedia. Para ello confió en testimonios literarios que a estas alturas nos resultan conocidos: Plutarco, Estobeo, el escoliasta de Nubes de Aristófanes, Dionisio de Halicarnaso y Heroida $11 .^{23}$ Tras contrastar estos datos, Palmer estableció el argumento del Eolo de Eurípides en los siguientes términos:

Euripides dramatized the story in his 'Aelous', a play which greatly scandalized the Athenians. This play was probably the only source of Ovid's epistle, and we may guess accurately enough at its plot from the remarks of Stobaeus and Dionysius. Macareus having seduced Canace, and fearing the wrath of Aeolus for her and himself, tells Canace that he will persuade her father to allow him to marry her. He gains his father's consent after a specious argument: but meantime Canace's child is born. Aeolus, ignorant of its paternity, dooms her to die, and sends a sword to her. Macareus hearing of this goes again to Aelous, confesses all, and implores his pardon for her and himself. He succeeds, and rushes to Canace's chamber with the news, but only to find her dying of a self-inflicted wound, on which he slays himself with the same sword. The play must have been painfully tragical. (1898:381)

Así pues, Palmer creyó que Macareo le había prometido a Cánace matrimonio sin haberlo aún hablado con su padre, al que convencería después mediante algún tipo de artimaña. Como enseguida comprobaremos, su conjetura iba en la dirección correcta. 


\section{POxy 2457 y Heroidas 11: conexiones y desviaciones}

La publicación en 1961 de unos fragmentos con hipótesis antiguas para la Alcestis y el Eolo de Eurípides, POxy 2457, nos da nuevos datos sobre el argumento de la obra. A continuación, reproduzco el fragmento relativo a Eolo en la traducción de Hall (2006:74), a partir de la edición de Turner (1962):

Aeolus received from the gods the administration of the winds, and settled in the lands opposite Etruria, having begotten six sons and the same number of daughters. The youngest of them, Macareus, fell in love with one of this sisters and seduced her. She became pregnant and hid the birth by pretending sickness. The young man persuaded the father to marry his daughters to his sons, and the latter, falling in with the plan, appointed a marriage ballot for all. The instigator of the scheme failed in the draw, since the lot fell out for the girl he had seduced to become another's wife. Running together...the nurse about the baby...

POxy 2457 apoyaría la teoría de Welcker (1839:860-872) quien, basándose en el fr. 39 de la edición de Nauck (1889:373), había ya sugerido que los matrimonios entre los hijos de Eolo se decidían por sorteo. Macareo, que habría tenido éxito en convencer a su padre de que permitiese estos matrimonios incestuosos, no habría tenido suerte en el sorteo de esposas, siendo designada Cánace a otro de sus hermanos.

A la luz de POxy 2457, Lloyd-Jones (1963:443) afirmó que se despejaba cualquier duda que pudiese haber sobre el uso del Eolo de Eurípides como modelo literario de Heroida 11. Según Lloyd-Jones, este fragmento mostraba que el intento de Macareo por convencer a Eolo para que casase a sus hijos e hijas entre sí habría sido fructífero, por lo que el “Nubite felices Parca meliore sorores" [Casaos con mejor suerte, mis felices hermanas] (Ep. 11.107) de la Cánace ovidiana, al referirse a la inminente boda de sus hermanas, estaría demostrando que el sulmonés había utilizado la tragedia griega como texto fuente. Sin embargo, para Jacobson (1974:161) el pasaje ovidiano no estaría sugiriendo unas nupcias inminentes. En su opinión, no sería más que un reflejo del deseo frustrado de Cánace de casarse, especialmente si observamos cómo otras heroínas también utilizan la imagen de las antorchas nupciales, como es el caso de Hipsípila (Ep. 6.45-46). El deseo expresado como un imperativo ("nubite" [casaos]) podría, así pues, hacer referencia a un futuro distante e invisible, dando rienda suelta al anhelo de Cánace — que, recordemos, está escribiendo la carta a Macareo mientras sostiene la espada con la que se va a dar muertepara que sus hermanas tengan un mejor destino que el suyo. ${ }^{24}$

La réplica al argumento de Jacobson la dio Labate (1977:584-5), quien razonó de manera muy convincente que el proyecto de matrimonio entre Cánace y Macareo sí está presente en la carta ovidiana como una realidad frustrada -no un simple deseo-, modelada con autonomía y sagacidad a partir del texto euripideo. El reproche de Cánace a Eolo por haber convertido la que tendría que ser su boda en su funeral ("His mea muneribus, genitor, conubia donas?" [¿Tú, que me engendraste, con este presente dotas mi matrimonio?],

24 Jacobson (1974:161) incluso comparó la imagen de la Cánace ovidiana con la de Ajax (S. Aj. 550) suplicando, antes de su muerte, mejor suerte para su hijo. Asimismo, argumentó que el uso del imperativo en Cánace no tiene por qué implicar necesariamente un suceso inminente, sobre todo si leemos este pasaje en correlación con otra de las cartas ovidianas, la de Briseida a Aquiles, donde la heroína también utiliza un imperativo ("Mittite me, Danai" [Enviadme a mí, Dánaos] Ep. 3.127) que, de ningún modo, debemos entender con sentido de inmediatez, sino desiderativo. 
Ep. 11.101) se materializa enseguida en la siguiente escena: Himeneo huye con sus antorchas nupciales de aquella nefanda casa para dar paso a las negras Erinias, vengadoras de los delitos de consanguinidad (Ep. 11.102-106). La conversión de la ceremonia matrimonial que Cánace y Macareo habían planeado "in un rito di morte" no solo resulta coherente a la luz de POxy 2457, sino que además muestra la complejidad del relato ovidiano, que demanda ser leído como hipertexto de la obra euripidea (Labate, 1977:585). Al igual que sucede en el resto de la colección, la carta de Cánace exige un público activo, capaz de apreciar el texto con relación al continuum narrativo del que forma parte.

Por su parte, Verducci (1985:199-204) consideró que tras la lectura de este papiro quedaba demostrado que Heroida 11 no es una adaptación directa ni del tono ni del argumento del Eolo, sobre todo si tenemos en cuenta que el interés de Eurípides parece ser el tratamiento del tema del incesto y de sus consecuencias desde un punto de vista ético, y no el hecho en sí de la particular aventura amorosa en la que los hermanos se ven envueltos. Ovidio, asimismo, se distanció del original en ciertos momentos clave. Como bien señaló la investigadora (Verducci, 1985:199), el papiro da información específica sobre el embarazo de Cánace, que ella ocultaría fingiendo estar enferma. Dado que en POxy 2457 no hay mención de ningún intento de aborto, Verducci cree que la tentativa plasmada en Heroida 11 de deshacerse del niño es una invención ovidiana. ${ }^{25}$ En este sentido, Ovidio habría conseguido superar a su modelo mediante la alteración de ciertos sucesos que aparecían en el Eolo euripideo.

Sobre el final corrupto del fragmento editado por Turner, Xanthaki-Karamanou y Mimidou (2014:60) se preguntaron si debíamos entender que los que corren juntos son Macareo y Cánace tratando de escapar de su destino o si, por el contrario, son Eolo y el hijo al que le había tocado Cánace en suerte. Sea como fuere, parece claro que la nodriza intentó hacer algo con el bebé de los hermanos; seguramente, habría procurado protegerlo de Eolo, tal y como aparece en Ovidio. Una hipótesis que según estas investigadoras combinaría la versión de Turner con los testimonios de Sóstrato (Stob. Flor. 4.20.72 = FGrH 23 F 3) y Plutarco (Mor. 312c-d), sería entender que en la obra euripidea Eolo y el hijo destinado a casarse con Cánace habrían corrido a la habitación de esta para anunciarle el resultado del sorteo, encontrándose entonces con la nodriza y el bebé. Al darse cuenta de la verdad, Eolo habría enviado a Cánace la espada con la que la muchacha debería suicidarse.

Retomando el debate que con anterioridad expuse sobre si Cánace fue violada por Macareo o si, en cambio, fue simplemente seducida por él, parece ahora quedar manifiesto que al menos no hay evidencia de que ningún autor anterior a Ovidio hablase de una Cánace enamorada de su hermano, ${ }^{26}$ por lo que tal tratamiento podría ser otra innovación de nuestro sulmonés, algo

\footnotetext{
25 De todos modos, es interesante la apreciación de Casali (1998:705) sobre la ironía ovidiana que resultaría de mostrar a una Cánace 'enferma' de amor (Ep. 11.28-34), especialmente si el poeta hubiese tenido en cuenta la enfermedad con la que la muchacha intentaba camuflar su embarazo en la versión euripidea. Para un estudio específico de la ironía dramática presente en Heroida 11 véase Williams (1992).

26 En Heroidas encontramos, por primera vez, una Cánace enamorada. El poeta distancia a Cánace de las actitudes adoptadas por otras mujeres incestuosas, como Biblis, Mirra y Fedra (Met. 9.551-552, 10.331-333; Ep. 4.129-134), y elige en cambio presentarnos a una joven inocente, que en absoluto ha buscado de manera premeditada mantener relaciones con su hermano ("Nescio quem sensi corde tepente deum" [Sentí en mi ardiente corazón a no sé qué dios] Ep. 11.28). De todos modos, Labate (1977:589) apuntó, de manera muy oportuna, que faltan pruebas para descartar totalmente la posibilidad de que la Cánace euripidea hubiese correspondido también los sentimientos de Macareo.
} 
que realmente encajaría muy bien en su faceta como poeta del amor. ${ }^{27} \mathrm{Sin}$ embargo, quisiera expresar mis dudas sobre cómo parece haber sido dicha relación para la Cánace ovidiana. Si leemos con detenimiento la epístola, no parece que ella estuviese enamorada de Macareo desde el principio, sino que los versos 25-26 ("Cur umquam plus me, frater, quam frater amasti / Et tibi, non debet quod soror esse, fui?" [¿Por qué una vez, hermano, más que como hermano me amaste y fui para ti lo que no debe ser una hermana?]) podrían entenderse como un apoyo a la teoría de aquellos que sostienen que la joven fue seducida de algún modo por su hermano. Sólo después de que Macareo consiguiese atraerla, la joven habría acabado por inflamarse ella también ("Ipsa quoque incalui" [yo misma también me inflamé de pasión] Ep. 11.27). Si se compara con la vehemente actitud de reproche que el resto de heroínas ovidianas acostumbran manifestar ante la traición o abandono de sus amantes, se puede pensar que en este pasaje Cánace regaña a su hermano de un modo particularmente suave. ${ }^{28}$ El pathos de la heroína ovidiana, de hecho, no está dirigido a su enamorado, como cabría esperar si se contrasta su carta con las demás Heroidas, sino a Eolo, lo que refuerza la centralidad de este personaje por encima de Macareo ${ }^{29}$ y apuntala la deuda de Heroida 11 con el drama euripideo (Labate, 1977:590).

De todos modos, y aunque los versos de Cánace a Macareo no estén abriendo la prototípica secuencia de duros reproches al amante que sí encontramos en otras de las Heroidas, ${ }^{30}$ considero que tras la aparentemente tierna queja de la joven se esconde un asunto mucho más serio: la recriminación de que Macareo vulnerase su castidad al amarla como un hermano no debe hacer nunca con una hermana. Es cierto que en el siguiente dístico el uso de quoque está remarcando que se trató de un amor recíproco. Lo que aquí señalo es que parece haber sido incitado primero por Macareo, tal y como conocemos por versiones previas del mito. Esto, si bien no exonera de culpa a la muchacha, consigue que los lectores empaticen más con ella.

La empatía hacia Cánace es, en verdad, uno de los efectos centrales que provoca la carta ovidiana, siendo también una de las aportaciones más genuinas del poeta a la historia de los hermanos. Desde el inicio, la joven se presenta a sí misma más como víctima de su furioso padre que como una amante incestuosa (Murgatroyd; Reeves; Parker, 2017:125), lo que sin duda le anticipa el favor de los lectores. El verso inaugural está centrado en enfatizar, de hecho, la filiación entre Cánace y Eolo: de una manera totalmente despersonalizada (la heroína no menciona su nombre en ningún punto de la carta ${ }^{31}$, se muestra al público como la hija de Eolo ("Aeolis Aeolidae, quam non habet ipsa, salutem / Mittit et armata uerba notata manu" [La hija de Éolo envía al hijo de Éolo la salud que ella no tiene y unas palabras escritas con mano que empuña la espada] Ep. 11.1-2). ${ }^{32} \mathrm{~A}$ su patronímico recurre también la nodriza cuando descubre

27 Para analizar con mayor profundidad el papel de Ovidio como poeta consagrado al amor y la postura antibelicista y, por consiguiente, contraria a la épica que adopta en sus obras véase a Barchiesi (1994:13-49).

28 Así lo considera, también, Jacobson (1974:163).

29 A pesar de que es a él a quien se dirige formalmente la carta, coincidimos con Labate (1977:590) en que el papel de Macareo en la versión ovidiana del mito de Cánace es "molto modesto" y que los roles protagonistas los comparten la heroína y su padre, como enseguida argumentaré.

30 Véanse, por ejemplo, las cartas de Filis (Ep. 2.45,67,99) y Dido (Ep. 7.97,133,139).

31 Esta misma estrategia la sigue, en la colección ovidiana, Ariadna (Thorsen, 2014:45).

32 Sobre la importancia de este dístico inicial, que algunos editores (como Palmer, 1898, o Knox, 1996) han considerado espurio, véanse Rosati (1984) y Reeson (2001), quienes defienden su autenticidad. Este dístico, en el que aparece recogido el prototípico saludo epistolar entre emisor y destinatario, puede ser entendido 
que la muchacha está enamorada ("Aeoli", dixit, "amas" ["Hija de Eolo", dijo, "estás enamorada"] Ep. 11.34). Concordamos con Thorsen (2014:45) en que esta estrategia ayuda a remarcar enormemente la autoridad de la figura paterna, a la vez que añade ironía trágica al hecho de que Cánace, descrita en esta carta como la hija de su padre, vaya a perder a su propio hijo a manos del abuelo.

Eolo es, en efecto, el eje sobre el que gira la apertura de la misiva: antes incluso de que sepamos que Cánace ha mantenido relaciones con Macareo (algo que los lectores percibimos a partir del verso 24), la heroína nos muestra la situación de inminente suicidio a la que la fuerza su padre y nos describe la crueldad e ira que caracterizan a su progenitor (Murgatroyd; Reeves; Parker, 2017:125). Su furia, que se intensifica en la narración cuando descubre al niño de Cánace (Ep. 11.75-88), provocará el cruel asesinato del recién nacido. La inocencia del pequeño suscita la empatía de los lectores y, por extensión, alcanza de nuevo a su madre, quien, en este punto del relato, ya ha sido obligada por Eolo a suicidarse. ${ }^{33}$ En consecuencia, las estrategias narrativas desplegadas por Ovidio en esta carta acaban por hacer posible que el incesto y embarazo de Cánace no solo sean aceptables para los lectores, sino también extremadamente conmovedores (Murgatroyd; Reeves; Parker, 2017:125), ${ }^{34}$ lo que convierte el texto ovidiano en un relato original que aporta una visión más profunda y afectiva del mito de Cánace que las anteriores.

Por último, pero no por ello menos importante, quisiera recuperar el debate mitográfico existente alrededor de la figura de Eolo en la carta ovidiana a la luz de los datos proporcionados por POxy 2457. Estos fragmentos nos muestran que Eurípides confundía también al Eolo I, hijo de Helén, con Eolo III, el Hipótada. En primer lugar, porque nos lo describe como el ‘señor de los vientos' y lo sitúa en Tirrenia, para a continuación introducirlo también como padre de Macareo. En segunda instancia, porque este Eolo euripideo está dispuesto a casar a sus hijos e hijas entre sí del mismo modo que había hecho el Eolo de Odisea.

\section{Conclusiones}

POxy 2457 arroja luz sobre las confusiones presentes en Heroida 11 respecto a la identificación de Eolo, al hacer patente que estas iban en la misma línea que las que ya se daban en su principal modelo literario. Asimismo, de la revisión contrastada de $P O x y 2457$ con las otras versiones del mito de Cánace recogidas por la tradición se constata la originalidad de la epístola ovidiana, que difiere de las demás fuentes en ciertos momentos clave de la historia.

como una 'nota al pie alejandrina' del propio Ovidio, es decir, una referencia alusiva del poeta a su texto fuente, el Eolo de Eurípides (Reeson, 2001:40). Por otra parte, que el uso sustantivado de Aeolis como "hija de Eolo" solo aparezca en Ovidio (en Heroida 11 referido a Cánace y en Met. 11.444, 573 referido a Alcíone (Reeson, 2001:42), estaría ayudando a retratar la autoridad de Eolo a costa de la subordinación y despersonalización de sus hijas.

33 La petición que Cánace dirige a Macareo para que sus restos mortales sean enterrados con los de su hijo podría ser, según Reeson (2001:108), una nueva alusión al Eolo euripideo, ya que el trágico había usado un motivo similar en Medea al tratar la muerte de Creonte y su hija.

34 De manera muy acertada, Murgatroyd; Reeves; Parker (2017:125) analizaron cómo el lugar que ocupa la carta de Cánace dentro de la colección ovidiana fortalece este efecto: "Placement is also effective: this epistle is even sadder for coming right after Her. 10 with its humour and happy ending in the background; and Canace seems still more innocent and touching in constrast to the earlier incestous female in the collection (the experienced, lust-ful and harmful Phaedra of Her. 4)". 
De todos modos, la deuda de Ovidio con Eurípides, su modelo principal, es una constante en la carta. El sulmonés lo deja claro desde el inicio mismo de la misiva, cuando Cánace nos presenta su inminente muerte en clave de escena trágica: una escena para la que desea un espectador (spectator) que coincide con el causante de la tragedia, Eolo, al que la muchacha define aquí como autor (auctor) de una obra (opus) que culminará con su suicido:

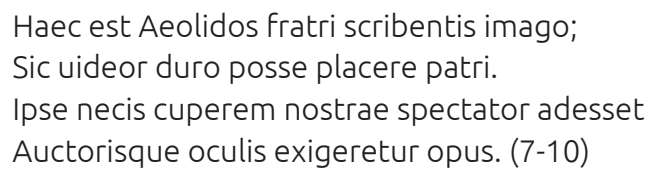

Esta es la imagen de la hija de Éolo al escribir a su hermano. Me parece que así puedo agradar a mi severo padre. Me gustaría que él estuviese presente, como espectador de mi muerte, y que acabase la obra a los ojos del autor.

La obra (opus) no es la epístola que Cánace está escribiendo, sino la tragedia desencadenada por su padre: es precisamente el desenlace trágico al que se ve abocada por su progenitor el que empuja a la heroína a escribir a Macareo. Los términos están cargados de dobles significados: el posible espectador interno de la imago scribentis de la escritora de la carta sería al mismo tiempo el auctor interno de la tragedia, su protagonista. Pero, inevitablemente, esta referencia nos impele a pensar también en Eurípides, autor -externo- de la tragedia que sirve de modelo a Ovidio. Los términos teatrales de la epístola actúan, en definitiva, como clave de lectura que nos orienta hacia su texto fuente trágico; de la tragedia original euripidea conserva la carta ovidiana, como ya se vio, el enorme protagonismo de Eolo. ${ }^{35}$.

Al invertir la enunciación prototípicamente masculina de la elegía y ceder la voz a Cánace para que la muchacha contase por primera vez su propia historia, ${ }^{36}$ en Heroida 11 Ovidio consiguió aunar tradición e innovación, construyendo un relato original y genuino. El poeta se sirvió magistralmente de las potencialidades que la carta como modalidad discursiva le otorgaba tanto para profundizar en la psicología humana como para experimentar con el entrecruzamiento del plano de la realidad y de la ficción, a nivel temático y técnico. En la carta de Cánace se observa claramente cómo bajo la apariencia de veracidad y espontaneidad propias del género epistolar Ovidio está articulando un complejo relato, a todas luces ficticio, que forma parte de un continuum narrativo de mayor alcance, con una trayectoria ya consolidada (aunque no exenta de problemas) en la tradición literaria y mitográfica anterior, a la que el poeta consigue aludir de manera inteligente e irónica a lo largo de su epístola.

35 Es interesante destacar cómo Ovidio juega con los dos niveles de autoría y recepción que se dan en la carta, toda vez que se articula como una epístola escrita por Cánace (aunque su autor real es Ovidio) y dirigida a Macareo (aunque los lectores reales somos todos aquellos que nos acercamos al texto). De manera muy inteligente, los versos ahora mencionados ponen de manifiesto los desdoblamientos que permite la modalidad de la epístola ficticia: auctor y opus sólo aluden a la tragedia de Eurípides en el nivel del autor externo de la carta, que es el de Ovidio, mientras que en el nivel interno, en el que Cánace es la narradora, sólo se pueden referir a Eolo y a su cruel orden. 


\section{Q Bibiliografía}

" Barchiesi, A. (1994). Il Poeta e ll Principe. Ovidio e il discorso augusteo. Rome: Laterza.

" Blázquez, F. (2005). Diccionario de mitología. Dioses, héroes, mitos y leyendas. Navarra: Verbo Divino.

" Camino Plaza, L. (2016). "Las voces femeninas en las Heroidas de Ovidio. Nuevas aproximaciones a la elegía de mujeres", ArtyHum 20, 132-143.

"Casali, S. (1998). "Ovid's Canace and Euripides' "Aelous": Two Notes on "Heroides" XI", Mnemosyne 51, 700-710.

»Dindorf, G. (1855). Scholia Graeca in Homeri Odysseam. Oxford: Oxford University Press.

»Fontán Barreiro, R. (1990). Eneida. Madrid: Alianza.

» Grimal, P. (1981). Diccionario de mitología griega y romana. Barcelona: Paidós.

» Hall, E. (2006). The Theatrical Cast of Athens. Interactions between Ancient Greek Drama and Society. Oxford: Oxford University Press.

»Jacobson, H. (1974). Ovid's Heroides. Princeton: Princeton University Press.

» Knox, P. (1996). Ovid's Heroides: Select Epistles. Cambridge: Cambridge University Press.

» Labate, M. (1977), "La Canace ovidiana e l“Eolo' di Euripide", ASNP7, 583-593.

» López, A.; Velasco, M.H. (2012). La mitología griega: lenguaje de dioses y hombres. Madrid: Arco Libros.

» Lloyd-Jones, H. (1963). "The Oxyrhynchus Papyri. 27", Gnomon 35, 433-455.

»Ibáñez Chacón, Á. (2014). Los Parallela minora atribuidos a Plutarco (Mor. 305A-316B): introducción, edición, traducción y comentario (tesis doctoral), Málaga: Universidad de Málaga.En:https://riuma.uma.es/xmlui/bitstream/handle/10630/8488/TDR_ IBAIEZ_CHACON.pdf?sequence=1\&isAllowed=y; obtenido el 02/04/2020.

» Morcillo, G. (2008). Cayo Julio Higino. Fábulas. Astronomía. Madrid: Akal.

" Moya, F. (1986). Ovidio. Heroidas, Texto revisado y traducido. Madrid: CSIC.

» Murgatroyd, P.; Reeves, B; Parker, S (2017). Ovid's Heroides. A New Translation and Critical Essays. Abingdon - New York: Routledge.

"Nauck, A. (1889). Tragicorum Graecorum fragmenta. Leipzig: Teubner.

" Palmer, A. (1898). Heroides. With the Greek translation of Planudes. Oxford: Oxford Clarendon Press.

» Reeson, J. (2001). Heroides 11, 13 and 14. A Commentary. Leiden: Brill.

» Rosati, G. (1984) "Aeolis Aeolidae... Sull'autenticità di un distico ovidiano (Her. 11, 0 a-b)", RFIC112, 417-426.

» Ruiz de Elvira, A. (1970). "Varia Mythographa”, Emerita 38, 291-310.

» Ruiz de Elvira, A. (1982). Mitología Clásica, Madrid: Gredos.

» Tapia Zúñiga, P. C. (2017). Homero. Odisea. Ciudad de México: Universidad Nacional Autónoma de México. 
"Thorsen, T. S. (2014). Ovid's Early Poetry. From his single Heroides to his Remedia amoris. Cambridge: Cambridge University Press.

" Torres Esbarranch, J. J. (2004). Diodoro de Sicilia. Biblioteca Histórica. Libros IV-VIII, Madrid: Gredos.

» Turner, E.G. (1962). "Hypotheses of Euripides' Alcestis and Aeolus". The Oxyrhynchus Papyri 27, 2457, 70-73.

»Verducci, F. (1985). Ovid's toyshop of the heart. Epistulae Heroidum. Princeton: Princeton University Press.

» Webster, T.B.L (1967). The Tragedies of Euripides. London: Methuen.

"Welcker, F. (1839). Die griechischen Tragödien mit Rücksicht auf den epischen Cyclus, Bonn: E. Weber. En: https://archive.org/details/diegriechischen00welcgoog; obtenido el 02/04/2020.

"Williams, G. (1992). "Ovid's Canace: Dramatic Irony in Heroides 11". CQ 42.1, 201-209.

" Xantaki-Karamanou, G.; Mimidou, E. (2014). "The Aelous of Euripides: Concepts and Motifs". BICS 57.1, 49-60. 
